\section{PATRIMONIO HISTÓRICO Y TUGURIOS. POLIIITCAS HABITACIONALES Y DE
RECUPERACIÓN DE LOS CENTROS HISTÓRICOS DE
BUENOS AIRES, CIUDAD DE MÉXICO Y QUITO}

\author{
VÍ́CTOR DELGADILLO POLANCO \\ UNIVERSIDAD AUTÓNOMA DE LA CIUDAD DE MÉXICO, CIUDAD DE \\ MÉXICO, MÉXICO, 2011.
}

RESEÑA DE SHARO LOPEZ JAVIER pone el análisis cruzado centrado en los estudios de caso, metodología que es aplicada en el estudio, y con la que se obtienen resultados que merecen ser incorporados y revisados en estudios posteriores.

Entre las principales conclusiones a que la investigación arriba está aquella en que los centros históricos analizados presentan estructuras especializadas y segregadas, las cuales fueron reforzadas por intervenciones puntuales y focalizadas realizadas a lo largo de estos años. De igual modo, el autor menciona que un factor común en los tres centros históricos es que se prioriza intervenciones en áreas capaces de generar mayores oportunidades de rentabilidad.

El autor concluye que los programas desarrollados buscaban, en el discurso, la permanencia de los residentes y el repoblamiento de los centros. Sin embargo, de facto, sucedió todo lo contrario, ya que se generaron proyectos que excluían poblaciones que no podían pagar por una vivienda o, en el peor de los casos, se generaban desplazamientos sociales. Además, el autor analiza las inversiones para cada caso, concluyendo que la mayoría de los proyectos se beneficiaron de la inversión de los gobiernos locales, en tanto, denota que existe un importante aporte de las agencias financiadoras como el BID y el Ayuntamiento de Andalucía. Las condiciones de financiamiento varían de caso en caso; en algunas se estableció un aporte-enganche, dirigido a los residentes que deseaban obtener una vivienda, los mismos que, entonces, debían realizar un aporte inicial para aquel fin. No obstante, en otros casos, se procedió a realizar subvenciones a las familias.

Con respecto a los costos de construcción de las viviendas, el autor señala que estos superan las expectativas iniciales, pues originan mayores gastos para los gobiernos locales y significan mayores aportes por parte de los beneficiarios. Además de las conclusiones mencionadas, el autor ofrece un estudio basado en datos cuantitativos y cualitativos, lo que permite entender con mayor claridad el fenómeno analizado.

Finalmente, el libro representa un registro infaltable en los estudios sobre los centros históricos y vivienda tugurizada.
Víctor Delgadillo, académico mexicano, es profesor a tiempo completo del Colegio de Humanidades y Ciencias Sociales de la UACM, profesor visitante en diversas uni-
Delgadillo (2011) afirma que no es posible realizar un estudio comparado de los centros históricos, debido a que los programas y proyectos fueron realizados en diferentes contextos económicos, políticos y con grandes disparidades sociales, por ello pro- 